\title{
Apogee Measurement of a Polyvinyl Chloride Rocket Using a Sugar Composite Propellant and Open Source Computer Rocket Simulation Software
}

\author{
Iguniwei B.Paul \\ Post Graduate School \\ Nigeria Defence Academy \\ Kaduna, Nigeria
}

\author{
Mohammed Y'au \\ Department of Chemistry \\ Nigerian Defence Academy \\ Kaduna, Nigeria
}

\author{
S. O. Okeniyi \\ Department of Chemistry \\ Nigerian Defence Academy \\ Kaduna, Nigeria
}

\begin{abstract}
The Bokoharam insurgency against the Nigerian State and the Nigerian Military effort at Counter insurgency operation, is a catalyst for this research, in to the apogee flight measurement of a locally constructed polyvinyl rocket with a sugar composite propellant, using an open source computer simulation software. The weight and dimensions of the locally constructed rocket with the dimensions and weights of 3 BATES propellant grains was imputed in to the open rocket computer software, creating a 3 Dimension model of the rocket. A simulation for peak altitude was initiated and an apogee of 729 meters was obtained. The result shows a potential application in infantry rocketry for close quarter battles.
\end{abstract}

Keywords: Bokoharam, Military, Apogee, Open source, Sugar, Propellant, Rocket and Simulation

\section{INTRODUCTION}

Chemists have always played the very fundamental role in the synthesis of propellants, be it for propelling a cannon ball, 7.62 by 59 ammunition, an artillery round, a free flight infantry rocket or a research rocket. The Bokoharam Insurgency against the Nigerian state and their unconventional asymmetric battle methodology [1] has led to this research of the local construction of a pvc rocket and simulate its apogee in a computer environment using a sucrose composite propellant.

The dearth of specific response to the speed with which the insurgents produce their explosives, IEDs etc as compared to the Nigerian military conventional logistic chain of supply is also an indicator for a change of approach. One of which is to produce quickly and easily certain weapons like the short range infantry rockets which would impact a close quarter battle often engaged in my the insurgents. This research attempts to show that cheap materials like polyvinyl chloride (pvc) sucrose and potassium nitrate can be used to propel a rocket, which when equipped with a destructive warhead can, be deployed against the insurgent enemy.

According to [2] Infantry Rocket Systems are man-portable direct fire weapons usually smaller than field artillery rockets. Anti-tank rockets are the most common infantry rocket system. They are designed to be carried by the individual soldier and fired from the shoulder. Examples of Free Flight Infantry rockets are the Light Anti-Armour Weapon (LAW) and an improved version of the LAW code named FGR-17 VIPER.

Sugar propellants like the KNSU are moderate performance propellants in which the binder fuel is one of the common sugars (sucrose, dextrose \& maltose etc). Technically KNSU is a composite propellant since it has a separate fuel and oxidizer component.
Potassium nitrate will not burn at all on its own, unless it is presented with a fuel source like sugar. When these two components are mixed together in a fuel-oxidizer matrix, the combustion is violent because of the rich source of oxygen from the $\mathrm{KNO}_{3}$. This kind of combustion reaction according to [3] is represented stoichiometrically as: $\mathrm{C}_{12} \mathrm{H}_{22} \mathrm{O}_{11(\mathrm{~s})}+6.3 \mathrm{KNO}_{3(\mathrm{~s})} \longrightarrow 4 \mathrm{CO}_{2(\mathrm{~g})}+5 \mathrm{CO}_{(\mathrm{g})}+8 \mathrm{H}_{2} \mathrm{O}_{(\mathrm{g})}+$
$3 \mathrm{H}_{2(\mathrm{~g})}+3 \mathrm{~N}_{2(\mathrm{~g})}+3 \mathrm{~K}_{2} \mathrm{CO}_{3(\mathrm{l})}+0.3 \mathrm{KOH}_{(\mathrm{l})}$

However the binder-fuel is not a polymer and is already partially oxidized. These two properties provide two useful characteristic of the propellant, first the binder decomposes more rapidly, than does the polymer, and so a lower-energy oxidizer such as $\mathrm{KNO}_{3}$ will be employed with excellent results. Secondly, a lower proportion of oxidizer can be used with good results. Sugar propellants have been found to be intermediate in performance [4]. Typical delivered specific impulse is between 115 - 130 seconds, which is not dependent on the fuel.

\section{LITERATURE REVIEW}

The firepower of Rockets and Missiles, combined with sustaining the bombing Tempo significantly led to the weakness at home (in Germany) of the German war-fighting capabilities hence the ultimate defeat by the Allied combined Bombing offensive against Nazi Germany during the period of 1943-1945 [5].Few declassified literature on Military Rockets exists, not because of lack of research, but because of the classified nature of military research [6] Some of the most common rockets powered by solid propellant motors are (i) the Milan Infantry anti-Tank Missile (Ballistite) (ii) the soviet Anti Tank AT-4 Missile (cordite). However a recent contemporary effective deployment of rockets in warfare was found in the Hezbollah Israel war of 2006 [7] 


\begin{tabular}{|l|c|}
\hline \multicolumn{2}{|l|}{ Some Common Propllants } \\
\hline Potassium Nitrate /Sugar \\
(KNSU)
\end{tabular}

Table 1: Specific Impulse (Isp) of Some Common Propellants

[8] Reported the re-crystallization process of KN/Sucrose which resolves some limitations of the use $\mathrm{KN} /$ sucrose. He also reported the melting of $\mathrm{KN} /$ sorbitol in a boiling-water bath. The propellant mix was enclosed in a plastic bag and immersed in hot water. This is the safest method yet of melting sugar propellants. Further literature has shown that there are different types of sugar used for rocket propellant Apart from sucrose, dextrose and sorbitol-a sugar alcohol are commonly use too.

\section{MATERIALS AND METHODS}

\subsection{Materials}

(i) Sucrose (ii) Potassium Nitrate (iii) cone (iv) Ziploc anti moisture bag (v) PVC tubes (vi) PVC sheet (vii) Acrylic Adhesive (viii) Heating Pan (ix) Heat resistant Thermometer (x) Hacksaw and cutting tool (xi) Measuring tape and Ruler (xii) Heat Resistant Hand gloves (xiii) Goggles (xiv) Digital Weighing Balance, Model Wuwangni 5kg+_ 1gm (xv) Thermostat controlled heat Source.

\subsection{Sample Collection}

Five hundred grams (500) of sugar (sucrose) manufactured by Dangote Company was obtained from the market, and was used without further purification. Industrial grade potassium nitrate was obtained from a chemical store. The sugar was kept in a polythene bags while the potassium nitrate was kept in its container as it was bought. PVC pipe was bought from the open market Method of Synthesis

\subsection{Method of Synthesis}

A modified Melt and Cast method of Richard Nakka [9] was used in the production of the varying composites of the propellants for this research work. This method involves grinding the sugar and potassium nitrate separately in to powdery form (to increase their surface area) and melting the sugar and mixed with potassium nitrate, making a batch of 200 grams of the KNSU mix. This mixture was done slowly! (To avoid a deflagration). The mixture was further heated using a hot plate to a melting temperature of $180^{\circ} \mathrm{C}$ forming a viscous paste, (figure 1) which was quickly poured into pvc BATES moulds (figure 2). It was allowed to cool, weighed and dimensions measured. It was stored in a desiccator to prevent contact with moisture. The composition ratio used was $65 \%$ Potassium Nitrate and 35\% Sugar)
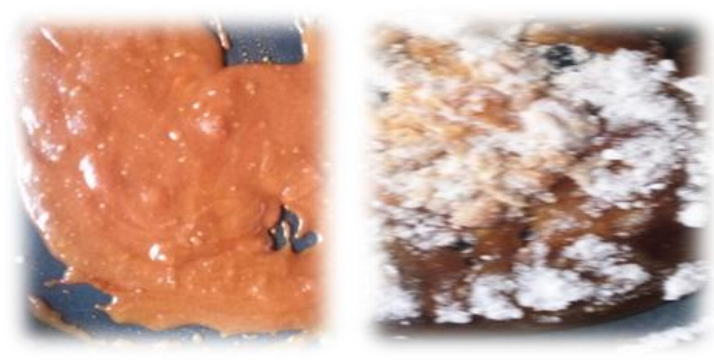

Figure 1 Melting of the Sucrose and Potassium Nitrate mixture

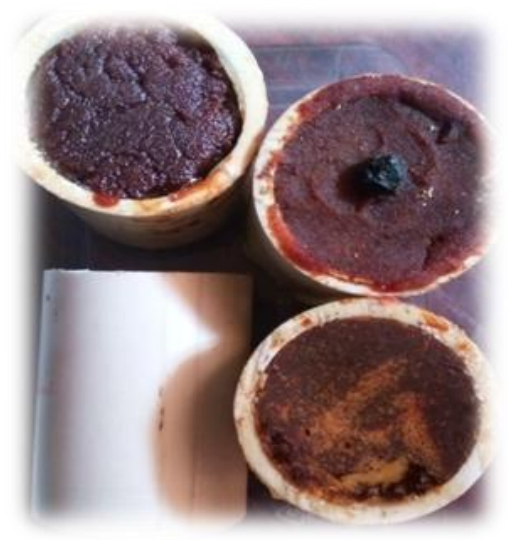

Figure 2 Cast BATES grains

\subsection{Rocket Sketch and Construction}

A workable design was sketched and constructed using Polyvinylchloride (PVC) tubing. All dimensions are in millimeters

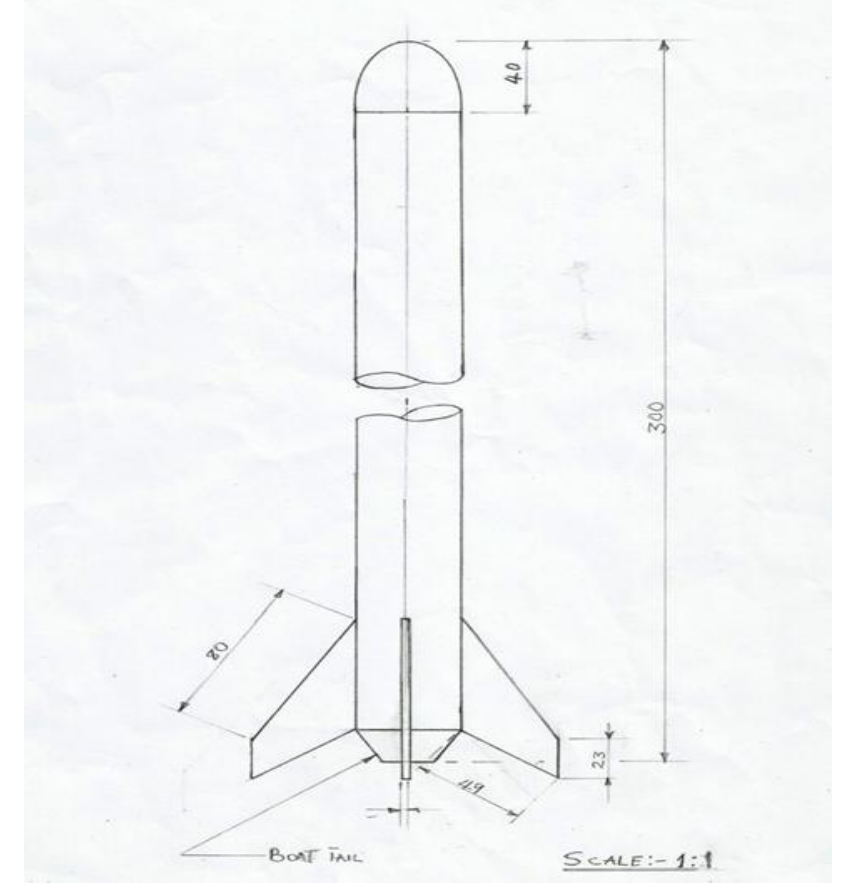

Figure 3 Design sketch with Dimensions of the PVC rocket 


\subsection{RESULTS AND DISCUSSION}

\subsection{Results}

The Ballistic Tests and Evaluation System (BATES) grain for composition A (Potassium nitrate 65\% and Sucrose 35\%) measured dimensions.

Table 1 Composition A weight and dimensions of the synthesized BATES Propellant

\begin{tabular}{|r|l|l|l|l|}
\hline /No & \multicolumn{1}{|r|}{$\begin{array}{r}\text { Weig } \\
\text { ht(g) }\end{array}$} & $\begin{array}{r}\text { L } \\
\text { ength } \\
(\mathbf{m m})\end{array}$ & $\begin{array}{r}\text { Dia } \\
\text { meter } \\
(\mathbf{m m})\end{array}$ & $\begin{array}{l}\text { Inner } \\
\text { Diameter } \\
\text { (mm) }\end{array}$ \\
\hline 1 & 78 & 51 & 33 & 5 \\
2 & 77.9 & 51 & 33 & 5 \\
3 & 78 & 51 & 33 & 5 \\
\hline
\end{tabular}

The BATES moulds for producing the BATES grains are uniform in dimensions, hence the uniform dimensions obtain from the grains measurement, except for the weight of the propellants.

Below is the life size of the constructed rocket, a product of the sketched rocket, of figure 3

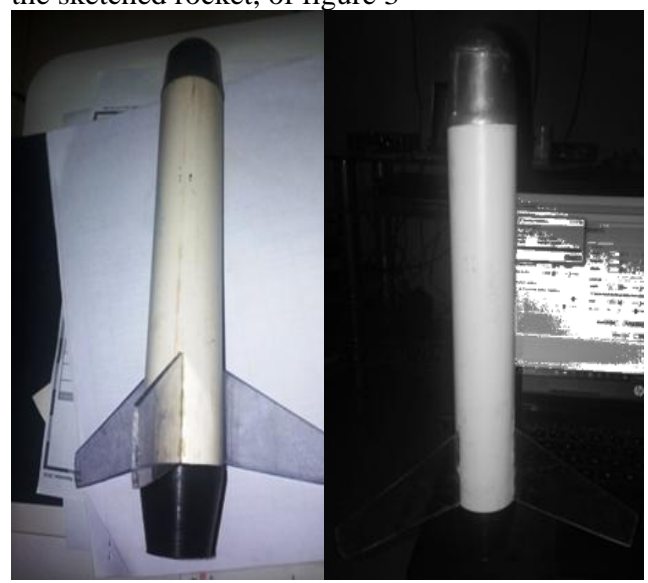

Figure 4: Constructed Rocket

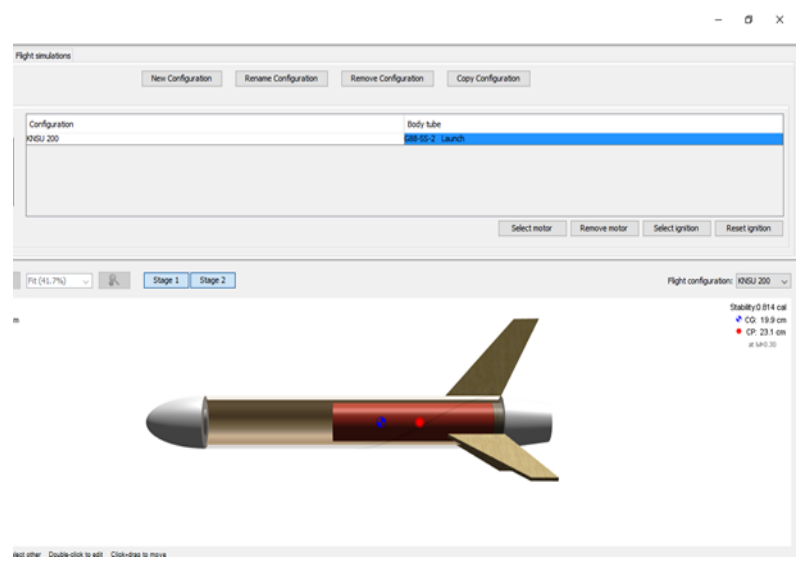

Figure 5: Screen shot of 3 Dimension designed rocket model
Table 2: Computer rocket flight performance analysis

\begin{tabular}{|l|l|}
\hline Specific Impulse & 116 \\
BurnOut Altitude $\left(\mathrm{z}_{1}\right) \mathrm{m}$ & - \\
BurnOut Velocity $\left(\mathrm{v}_{1}\right) \mathrm{ms}^{-1}$ & 104 \\
Apogee $\left(\mathrm{z}_{2}\right)$ Peak Altitude m & 729 \\
Peak Altitude Time $\left(\mathrm{t}_{2}\right)$ secs & 10.1 \\
\hline
\end{tabular}

\subsection{Discussion}

Table 1 shows the dimensions and the weight of the BATES grains. Apart from the small variations in weights of the grains, other parameters like the internal diameter and the length of the BATES grains are the same. This is because these parameters are intrinsic for the grains to be qualified as a BATE grain. The small deviation in the weights of KNSU grains may be due to rapid cooling of the molten propellant becoming more viscous during pouring in to the pvc moulds creating pockets of tiny air bubbles [10].

Figure 4 is the completed life size of the test rocket. Which was built on the design parameters from figure 3. It was ensured that the rocket is stable by locating the Centre of gravity (CG) and the Centre of Pressure (CP) according to [11]. Figure 5 shows the 3 dimension screen shot of the designed rocket, using the open rocket software [12]. The design was based on the sketched dimensions of figure 3. It enabled the KNSU composite propellant and the rocket to be simulated for some of the performance parameters as listed in Table 2.

From the design of the rocket and the synthesis of the propellant, it can be deduced that the propellant and the PVC material has a production advantage because of its simplistic production process, eliminating error through the use of the computer simulation software. The apogee distance of $729 \mathrm{~m}$ indicates a viable military application in short range infantry operations against the Bokoharam insurgents in the Northeastern region of Nigeria. The choice of selection of the materials: pvc, sucrose and potassium nitrate ensures a readily supply if and when the rocket is weaponised for military operations and confers huge economic advantage in terms of cost of procurement and the speed of field deployment.

\subsection{CONCLUSION}

A KNSU propellant was synthesized successfully using the Melt and Cast method. The BATES grain type of the KNSU propellant was used to propel a rocket in a computer simulated environment successfully to an apogee of $729 \mathrm{~m}$, a distance well over half a kilometer. This shows an important potential for military use of this propellant in infantry rocketry and close quarter battles (once the rocket is fitted with an explosive charge) as we are experiencing in Nigeria's Northeastern counter insurgency operations against the Bokoharam Insurgents. 


\subsection{ACKNOWLEDGEMENT}

I am grateful to Dr Omale and Dr Mohammed Y'au both of the Department of Chemistry, the Nigerian Defence Academy, Kaduna. Nigeria, for their fundamental support and professional inputs.

\section{REFERENCES}

[1] Michael, E., Alan, R., \& Russell, P. (Eds.). (2004) Future Armies Future Challenges -Land warfare in the information Age. Crow's Nest, Australia.

[2] MIL-HDBK-762, Design of Aerodynamically Stabilized free Rockets, Volume One (1990) US Army Missile Command, Military Handbook. Redstone Arsenal. pp 23-24

[3] Smiley, J. (2013) Easy PVC Rockets.pdf. Create space Independent Publishing. Retrieved from www.amazon.com

[4] Lesilie, S. \& Yawn, J. (2002) Proposal for the inclusion of $\mathrm{KNO}_{3} /$ Sugar Propellants in the Tripoli Research Agency (TRA) Experimental Rocketry Program. A Technical Report Retrieved from www.4sightinc.com/stu/docs/sugar_Pro_Proposal.pdf

[5] Michael, E., Alan, R., \& Russell, P. (Eds.). (2004) Future Armies Future Challenges -Land warfare in the information Age. Crow's Nest, Australia

[6] Krieger, F.J.(1960) The Russian Literature On Rocket Propellants, Physics Division. The Rand Corporation. Presented at the $137^{\text {th }}$ National Meeting of the American Chemical Society in Cleaveland Ohio. April 81960.

Retrieved March, 2016 from www.rand.org

[7] Rubin, U. (2007) The rocket Campaign Against Israel, 2006 Labanon War. MidEast Security and Policy Studies No 71. The Begin-Sadat Center of Strategic Studies, BAR-ILAN UNIVERSITY, Ramat Gan, Israel

[8] Lesilie, S. \& Yawn, J. (2002) Proposal for the inclusion of $\mathrm{KNO}_{3} /$ Sugar Propellants in the Tripoli Research Agency (TRA) Experimental Rocketry Program. A Technical Report Retrieved from www.4sightinc.com/stu/docs/sugar_Pro_Proposal.pdf

[9] Nakka, R.A. (1984) Solid Propellant Rocket Motor Design and Testing. A Thesis Presented to the Department of Mechanical Engineering, University of Manitoba.

[10] Nakka, R.A. (2007) Sugar Motors (pdf) Retrieved April 2016 from www.nakka-rocketry.net

[11] Ponder, D.M. (2013) Designing Your Own Model Rocket (pdf) retrieved from www.ohio4h.org

[12] Sampo Niskanen, OpenRocket Simulation software. Downloaded September 2015 from http://openrocket.info/ 